\title{
Preface to a Special Issue Celebrating the Birth Centenary of Professor C. R. Rao
}

\author{
Ravi Khattree $^{1} \cdot$ Sreenivasa Rao Jammalamadaka ${ }^{2} \cdot$ M. B. Rao ${ }^{3}$
}

Accepted: 3 May 2021 / Published online: 16 July 2021

(c) Grace Scientific Publishing 2021

It is indeed our pleasure to bring this special issue of the Journal of Statistical Theory and Practice to celebrate the birth centenary of Prof. C. R. Rao. Most of us would be delighted to meet a person who is hundred years young, leave alone knowing a giant personality who had a very active and visible professional presence for 75 long years. But Prof. C. R. Rao has always been in a class of his own, and his larger than life presence serves as an inspiration for all his colleagues, students, and admirers who know him.

Our associations with Prof. Rao date back several decades. Two of us (RK and SRJ) have been his PhD students and the third (MBR) has closely worked with him on a number of academic projects. As his students at the Indian Statistical Institute and at the University of Pittsburgh, albeit at different times, our academic trainings were heavily influenced by Prof. Rao's ideas and his research work, and that continues to be the case till today. The same can be said, we are sure, for most of his students and close coworkers. Thus, this special issue of invited and refereed articles titled "Celebrating the Birth Centenary of Professor C. R. Rao" is a collective way of showing the contributors' appreciation and of paying homage by generations of students and colleagues, to a historical personality who has touched so many livesdirectly or indirectly and academically as well as by way of example.

As one would expect, the list of authors in this volume extends over three academic generations and the breadth of topics goes far beyond what one would call as Rao's research areas. Nonetheless, in most of these articles, one will still find Prof. Rao's imprint and influence of ideas that directly or indirectly connect to him.

Ravi Khattree

khattree@oakland.edu

Sreenivasa Rao Jammalamadaka rao@pstat.ucsb.edu

M. B. Rao

raomb@ucmail.uc.edu

1 Oakland University, Rochester, Michigan, USA

2 University of California, Santa Barbara, Santa Barbara, California, USA

3 University of Cincinnati, Cincinnati, Ohio, USA 
Appropriately, in the process of editing this special issue and while reading these articles critically, our admiration for Prof. Rao's work has only grown further. We hope that our readers will also feel the same way.

Publisher's Note Springer Nature remains neutral with regard to jurisdictional claims in published maps and institutional affiliations. 